\title{
Phenylketonuria: reduced tyrosine brain influx relates to reduced cerebral protein synthesis
}

Martijn J de Groot ${ }^{1,2+}$, Marieke Hoeksma ${ }^{1,2+}$, Dirk-Jan Reijngoud ${ }^{2,3}$, Harold W de Valk ${ }^{4}$, Anne MJ Paans ${ }^{5}$, Pieter JJ Sauer ${ }^{1,3}$ and Francjan J van Spronsen ${ }^{1,3^{*}}$

\begin{abstract}
Background: In phenylketonuria (PKU), elevated blood phenylalanine (Phe) concentrations are considered to impair transport of large neutral amino acids (LNAAs) from blood to brain. This impairment is believed to underlie cognitive deficits in PKU via different mechanisms, including reduced cerebral protein synthesis. In this study, we investigated the hypothesis that impaired LNAA influx relates to reduced cerebral protein synthesis.

Methods: Using positron emission tomography, L-[1- $\left.{ }^{11} \mathrm{C}\right]$-tyrosine $\left({ }^{11} \mathrm{C}-\mathrm{Tyr}\right)$ brain influx and incorporation into cerebral protein were studied in 16 PKU patients (median age 24, range 16 - 47 years), most of whom were early and continuously treated. Data were analyzed by regression analyses, using either ${ }^{11} \mathrm{C}$-Tyr brain influx or ${ }^{11} \mathrm{C}-\mathrm{Tyr}$ cerebral protein incorporation as outcome variable. Predictor variables were baseline plasma Phe concentration, Phe tolerance, age, and ${ }^{11} \mathrm{C}$-Tyr brain efflux. For the modelling of cerebral protein incorporation, ${ }^{11} \mathrm{C}-$ Tyr brain influx was added as a predictor variable.

Results: ${ }^{11} \mathrm{C}-$ Tyr brain influx was inversely associated with plasma Phe concentrations (median 512, range $233-$ $1362 \mu \mathrm{mol} / \mathrm{L}$; delta adjusted $\left.\mathrm{R}^{2}=0.571, \mathrm{p}=0.013\right)$. In addition, ${ }^{11} \mathrm{C}$-Tyr brain influx was positively associated with ${ }^{11} \mathrm{C}-\mathrm{Tyr}$ brain efflux (delta adjusted $R^{2}=0.098, p=0.041$ ). Cerebral protein incorporation was positively associated with ${ }^{11} \mathrm{C}-\mathrm{Tyr}$ brain influx (adjusted $R^{2}=0.567, p<0.001$ ). All additional associations between predictor and outcome variables were statistically nonsignificant.

Conclusions: Our data favour the hypothesis that an elevated concentration of Phe in blood reduces cerebral protein synthesis by impairing LNAA transport from blood to brain. Considering the importance of cerebral protein synthesis for adequate brain development and functioning, our results support the notion that PKU treatment be continued in adulthood. Future studies investigating the effects of impaired LNAA transport on cerebral protein synthesis in more detail are indicated.
\end{abstract}

Keywords: Phenylketonuria, Phenylalanine, Tyrosine, Blood-brain barrier, Cerebral protein synthesis, Positron emission tomography

\footnotetext{
* Correspondence: f.j.van.spronsen@umcg.nl

${ }^{\dagger}$ Equal contributors

'Department of Metabolic Diseases, Beatrix Children's Hospital, University

Medical Center Groningen, University of Groningen, Groningen, the

Netherlands

${ }^{3}$ Center for Liver, Digestive and Metabolic Diseases, University Medical Center

Groningen, University of Groningen, Groningen, the Netherlands

Full list of author information is available at the end of the article
} 


\section{Background}

Phenylketonuria (PKU; OMIM 261600) is an inborn error of metabolism characterized by the inability to convert phenylalanine (Phe) to tyrosine (Tyr), caused by the deficiency of hepatic phenylalanine hydroxylase (EC 1.14.16.1). Untreated, PKU results in markedly elevated blood Phe concentrations, low-to-normal blood Tyr concentrations, and severe mental retardation [1]. The cornerstone of current treatment is reducing blood Phe concentrations, achieved in most patients by dietary Phe restriction combined with a Phe-free amino acid mixture [1]. When initiated early in life and followed continuously, this treatment prevents mental retardation [1], but mild reductions in intelligence quotient and impaired executive functioning remain [2-8]. Although it is clear that blood Phe concentrations throughout life closely relate to cognitive outcome in PKU [1], the pathophysiological consequences of elevated blood Phe concentrations are unknown [9-11].

Among others, reduced cerebral protein synthesis (CPS) is a particularly important pathophysiological mechanism [9-11]. CPS plays an essential role during cognitive development $[12,13]$, and reduced CPS results in cognitive deficits in several disorders $[13,14]$. Our group was the first to study CPS in PKU patients [15]. In this exploratory study, ${ }^{11} \mathrm{C}$-Tyr cerebral protein incorporation was analyzed in five early and continuously treated PKU patients, showing a tendency for reduced CPS at increasing blood Phe concentrations. In a follow-up paper describing sixteen patients, we showed that CPS indeed decreases significantly with increasing blood Phe concentrations [16].

Reduced CPS in PKU is believed to result from impaired transport of large neutral amino acids (LNAAs) across the blood-brain barrier (BBB). These LNAAs (Phe, valine, isoleucine, leucine, Tyr, tryptophan, threonine, histidine, and methionine) compete for transport by the LNAA type I (LAT1) transporter [17-20], for which Phe has the highest binding affinity [17-19]. Possibly, competition between LNAAs for blood-to-brain uptake also occurs at other transporters, such as SLCA19 and SLCA15 [21]. An elevated blood Phe concentration reduces uptake of non-Phe LNAAs from blood to brain in several fundamental studies [17-20]. Moreover, similar findings have been obtained in clinical studies. Reduced uptake of ${ }^{75} \mathrm{Se}$-selenomethionine has been reported in nine late-treated mentally retarded PKU patients with blood Phe concentrations mostly $>1000 \mu \mathrm{mol} / \mathrm{L}$, compared to mentally retarded patients without PKU [22]. More recently, Landvogt et al. (2008) reported on the striatal decarboxylation of 6 - $\left[{ }^{18} \mathrm{~F}\right]$-L-dihydroxyphenylalanine (FDOPA) in seven early and continuously treated PKU patients, with blood Phe concentrations between 510 and $1290 \mu \mathrm{mol} / \mathrm{L}$. FDOPA and LNAAs share the same transporter. Since arterial FDOPA concentrations were not measured in this study, FDOPA transport from blood to brain could not be modelled directly. However, an indirect approach assessing FDOPA transport, based on striatal FDOPA signal intensity changes during the first six minutes of the study, suggested reduced FDOPA transport from blood to brain [23].

The question arises whether impaired LNAA transport across the BBB is associated with the decrease in CPS observed in PKU patients. Thus far, no studies have simultaneously assessed LNAA BBB transport and CPS in PKU patients. Accordingly, we investigate the hypothesis that the observed CPS reduction in PKU patients is associated with impaired LNAA BBB transport.

\section{Patients, materials and methods Study cohort}

The study cohort is the same as that in Hoeksma et al. (2009) [16]. Sixteen adult PKU patients (seven males; age 16 - 47 years, median age 24 years) were included. Most patients $(13 / 16)$ had been diagnosed by neonatal screening and were continuously treated since. Three patients were late diagnosed, one of whom was identified at 3 years of age, after his sister was diagnosed by neonatal screening. The other two late diagnosed patients were identified after diagnostic work-up for developmental delay at 6 and 9 years of age, respectively.

Aimed Phe treatment ranges were $200-500 \mu \mathrm{mol} / \mathrm{L}$ for all ages until 2002, according to Dutch national guidelines. From 2002 onward, aimed ranges were $120-360 \mu \mathrm{mol} / \mathrm{L}$ for patients $<12$ years and $120-600 \mu \mathrm{mol} / \mathrm{L}$ for patients $\geq 12$ years [24]. Clinical severity of PKU was assessed by Phe tolerance, which is the amount of Phe that can be consumed daily while maintaining Phe concentrations within treatment range. Phe tolerance varied from 11 to $32 \mathrm{mg} / \mathrm{kg} /$ day at age 5 years, corresponding to $15 \%-45 \%$ of the recommended daily protein intake for age-matched healthy subjects. Phe tolerance in early childhood reliably predicts Phe tolerance later in life [25].

At the time of study, all patients were non-pregnant without pregnancy wish, and free of concomitant diseases. The Medical Ethical Committee of the University Medical Center Groningen approved the study design. Informed consent was obtained in all participants.

\section{Isotope preparation}

L-Tyr was obtained from Merck (Darmstadt, Germany). No-carrier-added L-[1- $\left.{ }^{11} \mathrm{C}\right]-\mathrm{Tyr}\left({ }^{11} \mathrm{C}\right.$-Tyr $)$ was synthesized via microwave-induced Bucherer-Strecker synthesis, as described previously [26]. Next, ${ }^{11} \mathrm{C}$-Tyr was dissolved in a $0.9 \%(\mathrm{w} / \mathrm{v}) \mathrm{NaCl}$ solution and passed through a sterile $0.22 \mu \mathrm{m}$ Millipore filter. This process resulted in an average radiochemical yield of $800 \mathrm{MBq}$, a radiochemical purity $>95 \%$, and a specific activity $>40 \mathrm{TBq} / \mathrm{mmol}$. A dose of $400 \mathrm{MBq}{ }^{11} \mathrm{C}$-Tyr, corresponding to $<10 \mathrm{nmol}{ }^{11} \mathrm{C}-\mathrm{Tyr}$, was administered to each patient. The effects of this dose on Tyr metabolic fluxes are negligible [27]. 


\section{PET data acquisition}

Data acquisition started after a $10-12 \mathrm{~h}$ overnight fast or a light breakfast with a very small amount of natural protein without amino acid supplement. Arterial and venous cannulae were inserted. A venous blood sample was taken to determine baseline plasma Phe and Tyr concentrations. Next, patients were positioned in the whole body PET scanner (ECAT EXACT $\mathrm{HR}^{+}$PET camera, Siemens/CTI, Knoxville, TN, USA). Hereafter, $400 \mathrm{MBq}$ of ${ }^{11} \mathrm{C}$-Tyr was infused in $8 \mathrm{ml} 0.9 \% \mathrm{NaCl}$ solution, followed by $32 \mathrm{ml}$ solution to flush the injection line, using a programmable infusion system (Medrad International, Maastricht, the Netherlands). Total injection time was $50 \mathrm{~s}$. During the next $50 \mathrm{~min}$, a dynamic PET scan was performed. The scanner was used in two-dimensional mode, imaging 63 consecutive two-dimensional images of $128 \times 128$ pixels over an axial length of $15.5 \mathrm{~cm}$. The in-plane resolution of the system was $4-5 \mathrm{~mm}$ full-width half-maximum, depending on the exact position in the plane. Spatial resolution was nearly isotropic in all three dimensions. The voxel size amounted to $16.5 \mathrm{~mm}^{3}$. The system was calibrated in absolute terms and cross-calibrated with an automated gamma well-counter (LKB Wallac, Turku, Finland). Throughout the scanning procedure, nineteen arterial blood samples were taken to measure plasma ${ }^{11} \mathrm{C}$ Tyr concentrations, as described by Willemsen et al. (1995) [27]: one sample every $10 \mathrm{~s}$ during the first minute after injection, one sample every $30 \mathrm{~s}$ during the next 4 minutes, and one sample at 10, 15, 20, 30, and $40 \mathrm{~min}$. For each patient, plasma ${ }^{11} \mathrm{CO}_{2}$ and ${ }^{11} \mathrm{C}$-protein concentrations were determined in nine samples, obtained at $0.5,1$, $2.5,5,10,15,20,30$, and $40 \mathrm{~min}$ after injection.

\section{Biochemical analyses}

After baseline arterial blood collection, samples were centrifuged at $2000 \mathrm{~g} \times 5 \mathrm{~min}$ at $4{ }^{\circ} \mathrm{C}$, and plasma was transferred to a clean tube. Arterial plasma Phe concentrations were measured using the AccQ Tag method (Waters BV, Breda, the Netherlands). Arterial plasma Tyr concentrations were measured by high-performance liquid chromatography with post-column ninhydrin derivatization on a Biochrome 20 amino acid analyzer (Pharmacia, Roosendaal, the Netherlands). Arterial plasma ${ }^{11} \mathrm{C}$ radioactivity was determined with a calibrated and automated gamma well-counter. Quantification of ${ }^{11} \mathrm{C}$-Tyr, ${ }^{11} \mathrm{C}$-protein, and ${ }^{11} \mathrm{CO}_{2}$ was performed as described by Willemsen et al. (1995) [27]. Plasma ${ }^{11} \mathrm{C}$ measurements were corrected for radioactive decay $\left(t_{1 / 2}=20.4 \mathrm{~min}\right)$ during sample manipulation.

\section{Modelling of ${ }^{11} \mathrm{C}$-Tyr fluxes}

A three-compartment model was used to calculate ${ }^{11} \mathrm{C}$ Tyr fluxes (Figure 1), adapted from the five-compartment kinetic model described by Willemsen et al. (1995) [27]. This modification increases the accuracy of rate constant determination. The following three compartments were defined: (1) a blood compartment of free ${ }^{11} \mathrm{C}-\mathrm{Tyr}$, (2) a brain compartment of free ${ }^{11} \mathrm{C}$-Tyr, and (3) a brain compartment of ${ }^{11} \mathrm{C}$-protein. With these three compartments, the following rate constants were defined: $\mathrm{k}_{2,1}$, describing the transport of free ${ }^{11} \mathrm{C}$-Tyr from blood to brain; $\mathrm{k}_{3,2}$, describing the incorporation of ${ }^{11} \mathrm{C}$-Tyr into ${ }^{11} \mathrm{C}$-protein in the brain; $\mathrm{k}_{2,3}$, describing the release of ${ }^{11} \mathrm{C}$-Tyr from ${ }^{11} \mathrm{C}$ protein in the brain; $\mathrm{k}_{1,2}$, describing the efflux of free ${ }^{11} \mathrm{C}$ Tyr from brain to blood.

This model was based on results obtained in animal studies, which indicate that certain metabolic ${ }^{11} \mathrm{C}-\mathrm{Tyr}$ pathways can be ignored within the time frame of our study $[26,28] .{ }^{11} \mathrm{C}$-Tyr can be metabolized to ${ }^{11} \mathrm{C}$-protein, ${ }^{11} \mathrm{C}$-3,4-dihydroxyphenylalanine $\left({ }^{11} \mathrm{C}\right.$-DOPA $),{ }^{11} \mathrm{C}$-p-hydroxyphenylpyruvic acid $\left({ }^{11} \mathrm{C}\right.$-HPPA), and ${ }^{11} \mathrm{C}$-p-hydroxy phenyllactic acid $\left({ }^{11} \mathrm{C}\right.$-HPLA). ${ }^{11} \mathrm{C}$-HPLA can be metabolized to ${ }^{11} \mathrm{CO}_{2}$ and next $\mathrm{H}^{11} \mathrm{CO}_{3}{ }^{-}$. Previous work on ${ }^{14} \mathrm{C}$ Tyr in rats has shown that $60 \mathrm{~min}$ after injection, the major metabolic pathway of ${ }^{14} \mathrm{C}$-Tyr is incorporation into ${ }^{14} \mathrm{C}$-protein [26]. In addition, the cerebral amount of ${ }^{14} \mathrm{C}$ incorporated into non-protein metabolites, including ${ }^{14} \mathrm{C}$ DOPA, was $<4 \%$ of the total cerebral amount of ${ }^{14} \mathrm{C}$ [26]. Similarly, the amounts of brain ${ }^{14} \mathrm{CO}_{2}$ and $\mathrm{H}^{14} \mathrm{CO}_{3}{ }^{-}$were negligible [26]. In line with these results, Cumming et al.

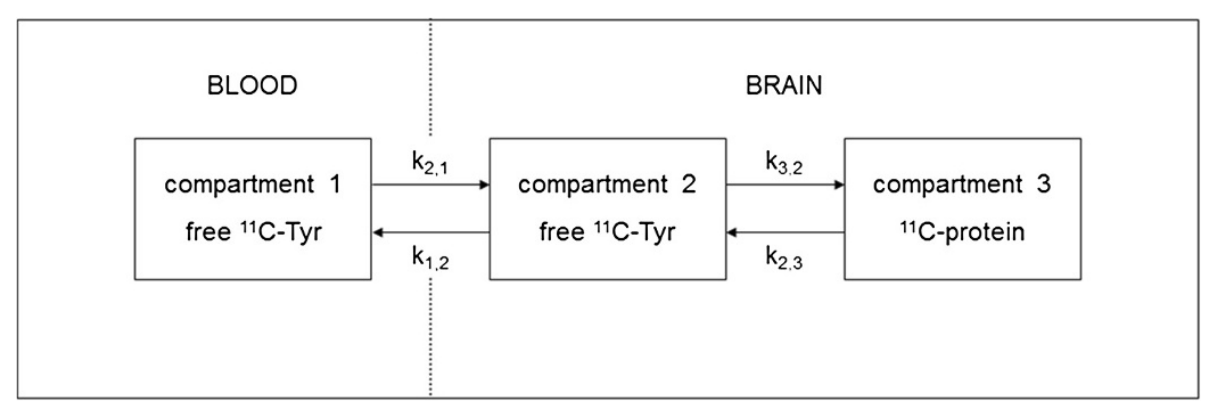

Figure 1 Three-compartment model of ${ }^{11} \mathrm{C}$ fluxes, adapted from Willemsen et al. (1995). Each rate constant $k_{A, B}$ reflects the unidirectional ${ }^{11} \mathrm{C}$ transport to compartment $\mathbf{A}$ from compartment B. Compartment 1: blood free ${ }^{11} \mathrm{C}$-Tyr; compartment 2: brain free ${ }^{11} \mathrm{C}$-Tyr; compartment 3: brain ${ }^{11} \mathrm{C}$-protein, i.e. ${ }^{11} \mathrm{C}$-Tyr incorporated into cerebral protein. 
(1998) described that in rats, ${ }^{3} \mathrm{H}$-Tyr is mainly metabolized into ${ }^{3} \mathrm{H}$-protein rather than ${ }^{3} \mathrm{H}$-DOPA [28]. Another study investigating CPS by ${ }^{11} \mathrm{C}$-leucine incorporation [29] showed that within a time frame of $110 \mathrm{~min}$, the contribution of 'recycled' ${ }^{11} \mathrm{C}$-leucine (i.e. leucine derived from proteolysis of ${ }^{11} \mathrm{C}$-protein reincorporated to ${ }^{11} \mathrm{C}$-protein) to the ${ }^{11} \mathrm{C}$-leucine incorporation rate is negligible.

Based on these studies, we made the following assumptions regarding the three-compartment model. First, ${ }^{11} \mathrm{C}$-Tyr is mainly metabolized to ${ }^{11} \mathrm{C}$-protein, and the contribution of brain non-protein ${ }^{11} \mathrm{C}$-metabolites $\left({ }^{11} \mathrm{C}\right.$ DOPA, ${ }^{11} \mathrm{C}$-HPPA, ${ }^{11} \mathrm{C}$-HPLA, ${ }^{11} \mathrm{CO}_{2}$, and $\left.\mathrm{H}^{11} \mathrm{CO}_{3}^{-}\right)$to total brain radiation is negligible within the time frame of our study. Second, the contribution of ${ }^{11} \mathrm{C}$ in the cerebral vasculature to brain ${ }^{11} \mathrm{C}$ signal equals $\sim 2.5 \%$ of total brain ${ }^{11} \mathrm{C}$ radiation. Third, the effluxes of ${ }^{11} \mathrm{C}$-protein, ${ }^{11} \mathrm{CO}_{2}$, and $\mathrm{H}^{11} \mathrm{CO}_{3}{ }^{-}$from brain to blood, as well as $\mathrm{k}_{2,3}$, can be neglected within the time frame studied.

For the purposes of this study, $\mathrm{k}_{2,1}$ was considered to reflect transport of non-labelled LNAAs across the BBB, and $k_{3,2}$ was considered to reflect CPS. Therefore, the primary parameters of interest in our study were $k_{2,1}$ (the transport of ${ }^{11} \mathrm{C}$-Tyr from blood to brain) and $\mathrm{k}_{3,2}$ (the incorporation of brain ${ }^{11} \mathrm{C}$-Tyr into brain ${ }^{11} \mathrm{C}$-protein). Of note, ${ }^{11} \mathrm{C}$-Tyr incorporation into ${ }^{11} \mathrm{C}$-protein is not identical to net CPS, nor does it necessarily reflect incorporation of non-labelled, non-Tyr amino acids [27]. Both outcome parameters were assessed in three regions of interest (ROIs), as described by Hawkins et al. (1989) [29] and shown in Figure 2. This regional approach was chosen because compartment analysis cannot be performed on a pixel-by-pixel basis, due to the stochastic variation in radioactivity data [27]. Thus, the compartment model was fitted to the ${ }^{11} \mathrm{C}$ radioactivity signal per ROI per sampling time point $\left(C_{\text {tis }}(t)\right)$, and to the arterial ${ }^{11} \mathrm{C}$ - $\mathrm{Tyr}$ plasma radioactivity signal at each time point $\left(\mathrm{C}_{\mathrm{pl}}(\mathrm{t})\right)$, using the MATLAB software package (MATLAB version 5, MathWorks Inc., Natick, MA, USA).

\section{Statistical analyses}

Testing for normality and homogeneity of variances was done using the Shapiro-Wilk test and Levene's test, respectively. Normally distributed variables with homogeneous variances are reported as mean $\pm \mathrm{SD}$. Nonnormally distributed variables and/or variables with inhomogeneous variances are given as range with median in parentheses.

Prior to multivariate analyses, multicollinearity was assessed by correlation analyses of predictor variables. Correlation coefficients $|\mathrm{r}|>0.80$ were considered to reflect statistically relevant multicollinearity. For normally distributed variables with homogeneous variances, Pearson's correlation test was used. Otherwise, correlation testing was done by Spearman's rank correlation test. Multiple linear regression analyses were done using a stepwise approach, with either $k_{2,1}$ or $k_{3,2}$ as outcome variables. For both outcome variables, baseline plasma Phe, Phe tolerance, age, and $k_{1,2}$ were used as predictor variables. For the $k_{3,2}$ multiple regression analysis, $k_{2,1}$ was additionally selected as a predictor variable. Baseline non-labelled plasma Tyr concentration was excluded as a predictor variable in all models, as it was involved in calculating ${ }^{11} \mathrm{C}$-Tyr fluxes and would thus by definition show high $r$-values.

Following multiple regression analyses, the assumptions of homoscedasticity, independence of errors, normality of error distribution, and linearity were evaluated. In addition, the presence of multicollinearity was again assessed, by analyzing variance inflation factor (VIF) and tolerance values. Statistical analyses were done using SPSS (Windows version 20, SPSS, Chicago, IL, USA). A two-sided p-value $<0.05$ was considered to be statistically significant.

\section{Results}

\section{Patient characteristics and ${ }^{11} \mathrm{C}$-Tyr fluxes}

Individual patient data are presented in Table 1. Baseline venous plasma Phe concentrations ranged from 233 to $1362 \mu \mathrm{mol} / \mathrm{L}(512 \mu \mathrm{mol} / \mathrm{L})$. Five of the sixteen subjects

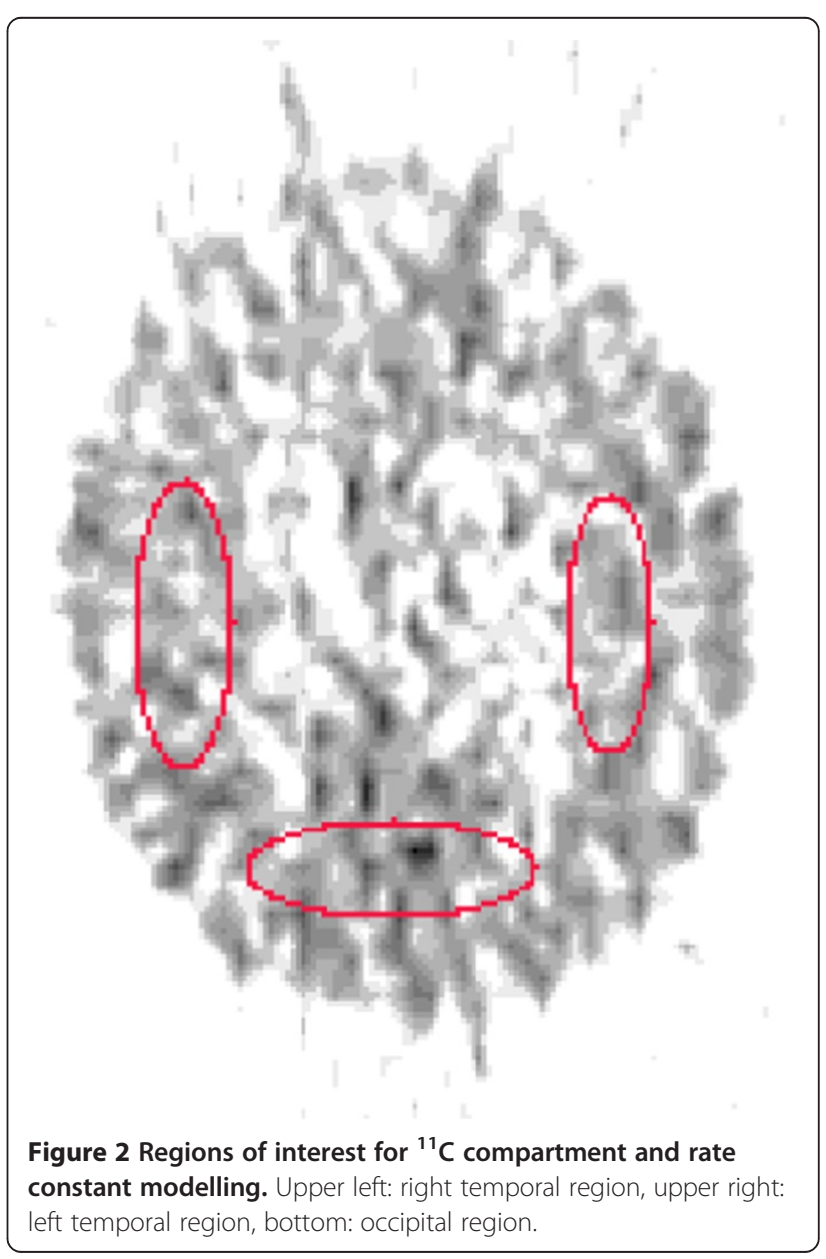


Table 1 Study cohort characteristics

\begin{tabular}{|c|c|c|c|c|c|c|c|}
\hline Patient & Age (yrs) & Phe tolerance (mg/kg/day) & Plasma Phe $(\mu \mathrm{mol} / \mathrm{L})$ & Plasma Tyr $(\mu \mathrm{mol} / \mathrm{L})$ & $\mathrm{k}_{2,1^{\mathrm{a}}}$ & $k_{3,2} b^{\prime}$ & $\mathrm{k}_{1,2}{ }^{\mathrm{c}}$ \\
\hline 1 & 16 & 28 & 233 & 66 & 0.055 & 1.06 & 0.073 \\
\hline 2 & 23 & 11 & 358 & 37 & 0.037 & 0.48 & 0.064 \\
\hline 3 & 23 & 12 & 361 & 32 & 0.046 & 0.71 & 0.077 \\
\hline 4 & 24 & 16 & 373 & 35 & 0.041 & 0.46 & 0.070 \\
\hline 5 & 26 & 31 & 375 & 47 & 0.031 & 0.50 & 0.052 \\
\hline 6 & 25 & 27 & 405 & 49 & 0.031 & 0.47 & 0.069 \\
\hline 7 & 23 & 20 & 411 & 87 & 0.037 & 0.70 & 0.072 \\
\hline 8 & 21 & 18 & 477 & 31 & 0.034 & 0.42 & 0.061 \\
\hline 9 & 22 & 32 & 546 & 42 & 0.033 & 0.54 & 0.057 \\
\hline 10 & 25 & 13 & 565 & 76 & 0.028 & 0.78 & 0.047 \\
\hline 11 & 20 & 19 & 586 & 38 & 0.039 & 0.55 & 0.085 \\
\hline 12 & 24 & 17 & 632 & 61 & 0.023 & 0.50 & 0.055 \\
\hline 13 & 21 & 15 & 805 & 35 & 0.027 & 0.36 & 0.066 \\
\hline 14 & 27 & 23 & 825 & 49 & 0.021 & 0.32 & 0.060 \\
\hline 15 & 47 & 14 & 1078 & 33 & 0.019 & 0.21 & 0.029 \\
\hline 16 & 33 & 12 & 1362 & 37 & 0.021 & 0.34 & 0.049 \\
\hline
\end{tabular}

Phe tolerance values were obtained at age 5 years. Patients 15 and 16 were treated from 6 and 9 years of age onward, respectively. In these patients, Phe tolerance was determined 6 months after treatment start. Phenylalanine and tyrosine plasma concentrations shown are baseline values. ${ }^{a}{ }^{11} \mathrm{C}-\mathrm{Tyr}$ transport from blood to brain (ml plasma/g brain tissue/min). ${ }^{\text {b }{ }^{11} \mathrm{C}-T y r}$ cerebral protein incorporation (nmol/g brain tissue/min). ${ }^{\mathrm{c}}{ }^{11} \mathrm{C}-\mathrm{Tyr}$ transport from brain to blood (ml plasma/g brain tissue/min).

studied had Phe concentrations above aimed treatment upper limit (i.e. $600 \mu \mathrm{mol} / \mathrm{L}$ ). Baseline venous plasma Tyr concentrations ranged from 31 to $87 \mu \mathrm{mol} / \mathrm{L}(40 \mu \mathrm{mol} / \mathrm{L})$. Mean rate of clearance of free ${ }^{11} \mathrm{C}$-Tyr by transport from blood to brain $\left(\mathrm{k}_{2,1}\right)$ was $0.033 \pm 0.010 \mathrm{ml}$ plasma/g brain tissue/min. Mean ${ }^{11} \mathrm{C}$-Tyr incorporation into cerebral protein $\left(\mathrm{k}_{3,2}\right)$ was $0.53 \pm 0.21 \mathrm{nmol} / \mathrm{g}$ brain tissue $/ \mathrm{min}$. Mean rate of clearance of free ${ }^{11} \mathrm{C}$-Tyr by transport from brain to blood $\left(\mathrm{k}_{1,2}\right)$ was $0.062 \pm 0.014 \mathrm{ml}$ plasma/g brain tissue/min.

\section{${ }^{11} \mathrm{C}$-Tyr transport from blood to brain}

The stepwise multiple linear regression with ${ }^{11} \mathrm{C}-\mathrm{Tyr}$ transport from blood to brain as dependent variable resulted in a significant model (adjusted $R^{2}=0.669$, $\mathrm{F}=16.182$, $\mathrm{p}<0.001)$. Parameters of this model are summarized in Table 2. In this model, baseline Phe concentration and $\mathrm{k}_{1,2}$ were significant predictor variables for ${ }^{11} \mathrm{C}-\mathrm{T} y \mathrm{r}$

Table 2 Multiple linear regression modelling for ${ }^{11} \mathrm{C}-\mathrm{Tyr}$ transport from blood to brain

\begin{tabular}{lccccc}
\hline & B & SE B & $\boldsymbol{\beta}$ & $\begin{array}{c}\text { Adjusted } \\
\mathbf{R}^{2} \text { change }\end{array}$ & $\mathbf{p}$ \\
\hline Baseline Phe & $-1.728 * 10^{-5}$ & 0.000 & -0.529 & 0.571 & 0.013 \\
\hline $\mathrm{k}_{1,2}$ & 0.301 & 0.132 & 0.417 & 0.098 & 0.041 \\
\hline Constant & 0.024 & 0.011 & n.a. & n.a. & 0.041 \\
\hline
\end{tabular}

Multiple regression model with ${ }^{11} \mathrm{C}$-Tyr transport from blood to brain as outcome variable, using baseline plasma Phe, Phe tolerance, age, and $\mathrm{k}_{1,2}$ as predictor variables. Only statistically significant predictor variables are shown. $\mathrm{k}_{1,2}:{ }^{11} \mathrm{C}-\mathrm{Tyr}$ transport from brain to blood. SE: standard error. transport from blood to brain ( $\Delta$ adjusted $R^{2}=0.571$, $\mathrm{p}=0.013 ; \Delta$ adjusted $\mathrm{R}^{2}=0.098, \mathrm{p}=0.041$, respectively). ${ }^{11} \mathrm{C}$ Tyr transport from blood to brain showed a negative partial correlation with baseline Phe concentration, indicating that at increasing baseline Phe concentrations, ${ }^{11} \mathrm{C}-\mathrm{Tyr}$ influx to brain is decreased. ${ }^{11} \mathrm{C}$-Tyr influx to brain showed a positive partial correlation with $\mathrm{k}_{1,2}$, indicating that with increasing efflux of ${ }^{11} \mathrm{C}$-Tyr from brain to blood, ${ }^{11} \mathrm{C}$-Tyr transport from blood to brain increases. Statistical analyses to verify the assumptions for multiple linear regression showed that the assumptions of homoscedasticity, independent errors, normality of error distribution, and linearity had been met. Correlation coefficients between predictor variables, as well as VIF and tolerance values, were consistent with no multicollinearity. Figure 3 shows the relation between ${ }^{11} \mathrm{C}$-Tyr transport from blood to brain and plasma Phe concentration .

\section{${ }^{11} \mathrm{C}$-Tyr cerebral protein incorporation}

The stepwise multiple linear regression with ${ }^{11} \mathrm{C}$-Tyr cerebral protein incorporation as dependent variable resulted in a significant model (adjusted $\mathrm{R}^{2}=0.567, \mathrm{~F}=20.642$, $\mathrm{p}<0.001$ ), with only ${ }^{11} \mathrm{C}$-Tyr transport from blood to brain as a significant predictor variable. Parameters of this model are summarized in Table $3 .{ }^{11} \mathrm{C}$-Tyr cerebral protein incorporation showed a positive partial correlation with ${ }^{11} \mathrm{C}$-Tyr transport from blood to brain. Thus, lower ${ }^{11} \mathrm{C}$-Tyr influx values were associated with lower ${ }^{11} \mathrm{C}$-Tyr cerebral incorporation values. Following the main analysis, 


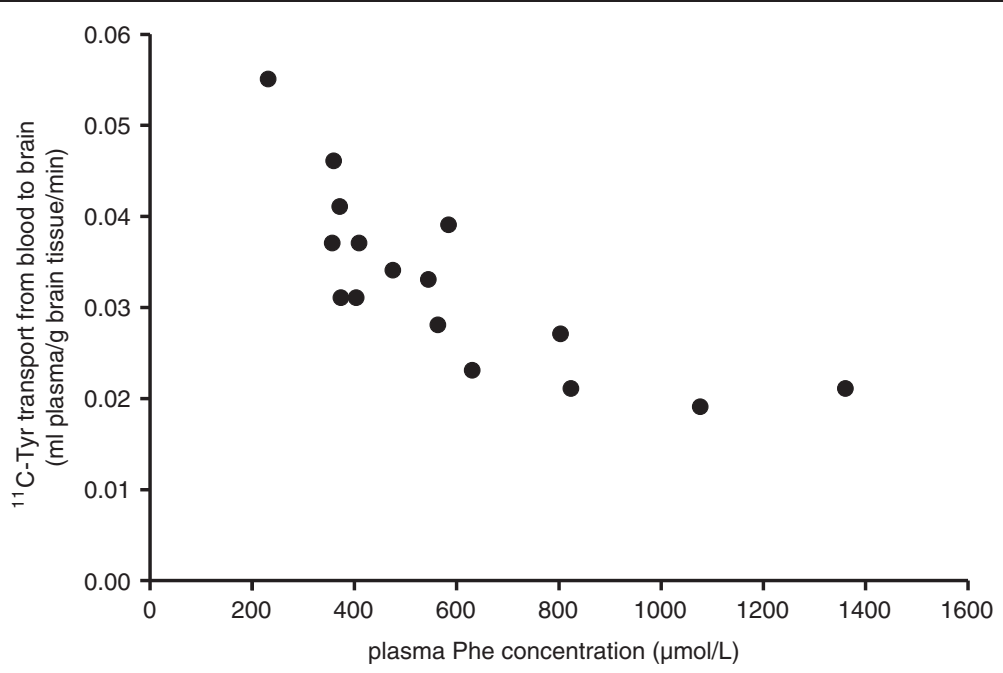

Figure 3 Relation between ${ }^{11} \mathrm{C}-\mathrm{Tyr}$ transport from blood to brain and plasma phenylalanine concentration.

additional analyses were performed to assess the assumptions for multiple linear regression. These analyses showed that the assumptions of homoscedasticity, independent errors, normality of error distribution, and linearity had been met. Correlation coefficients between predictor variables, as well as VIF and tolerance values, were consistent with no multicollinearity. Figure 4 shows the relation between ${ }^{11} \mathrm{C}$-Tyr cerebral protein incorporation and ${ }^{11} \mathrm{C}$-Tyr transport from blood to brain.

\section{Discussion}

This study is the first to simultaneously investigate LNAA transport from blood to brain and CPS in PKU patients. Our work can be summarized in two main findings. First, increased blood Phe concentrations are strongly associated with reduced ${ }^{11} \mathrm{C}$-Tyr transport from blood to brain. Second, reduced ${ }^{11} \mathrm{C}$-Tyr transport from blood to brain is strongly associated with reduced ${ }^{11} \mathrm{C}$ Tyr cerebral protein incorporation. Before discussing the results of this study, we will first address the strengths and limitations of our approach.

${ }^{11} \mathrm{C}$-Tyr transport from blood to brain and ${ }^{11} \mathrm{C}$-Tyr cerebral protein incorporation were calculated using a threecompartment model, adapted from [27]. This approach

Table 3 Multiple linear regression modelling for ${ }^{11} \mathrm{C}$-Tyr cerebral protein incorporation

\begin{tabular}{lccccc}
\hline & $\mathbf{B}$ & $\mathbf{S E} \mathbf{B}$ & $\boldsymbol{\beta}$ & Adjusted $\mathbf{R}^{2}$ change & $\mathbf{p}$ \\
\hline $\mathrm{k}_{2,1}$ & 16.303 & 3.588 & 0.772 & 0.567 & $<0.001$ \\
\hline Constant & -0.008 & 0.122 & n.a. & n.a. & 0.949
\end{tabular}

Multiple regression model with ${ }^{11} \mathrm{C}$-Tyr cerebral protein incorporation as outcome variable, using baseline plasma Phe, Phe tolerance, age, $\mathrm{k}_{1,2}$ and $\mathrm{k}_{2,1}$ as predictor variables. Only statistically significant predictor variables are shown. $\mathrm{k}_{2,1}:{ }^{11} \mathrm{C}$-Tyr transport from blood to brain. SE: standard error. differs from that in our previous study [16], which only allowed for quantification of CPS. Our current model allows for the assessment of multiple compartments and ${ }^{11} \mathrm{C}$-Tyr fluxes between these compartments. As outlined above, this three-compartment model is based on results found in animal studies $[26,28,29]$. It should be noted that these findings have not been validated in humans.

The assumptions for performing multiple linear regression analyses were met, indicating that our conclusions can be generalized to other PKU patient cohorts. Still, for extensive statistical analyses such as regression modelling with four to five predictor variables, a cohort size of sixteen subjects is relatively small. This relatively small sample size may have reduced the power of the regression analyses in our study. Although the nonsignificant predictor variables in our study may correlate to some extent with their corresponding outcome variables, these correlations should be weaker that the currently observed correlations.

In order to acquire reliable measurements, a steady state condition in each patient was required. To obtain such a condition, patients fasted prior to the study and refrained from taking amino acid formula. After an overnight fast, some patients consumed a light breakfast with a very limited amount of Phe, whereas other patients remained fasted. We consider the influence of the light breakfast to be minimal, as we previously showed that such a breakfast does neither affect blood Phe nor blood Tyr concentrations [30]. Similarly, one could hypothesize that ceasing amino acid formula intake could have affected blood Phe and Tyr concentrations during the study period. First, intake of amino acid formula could reduce Phe uptake at the gut-blood barrier, thus reducing blood Phe concentrations. Second, formula intake could increase blood Tyr concentrations. Whether these effects would in turn influence ${ }^{11} \mathrm{C}$-Tyr fluxes remains to be investigated. 


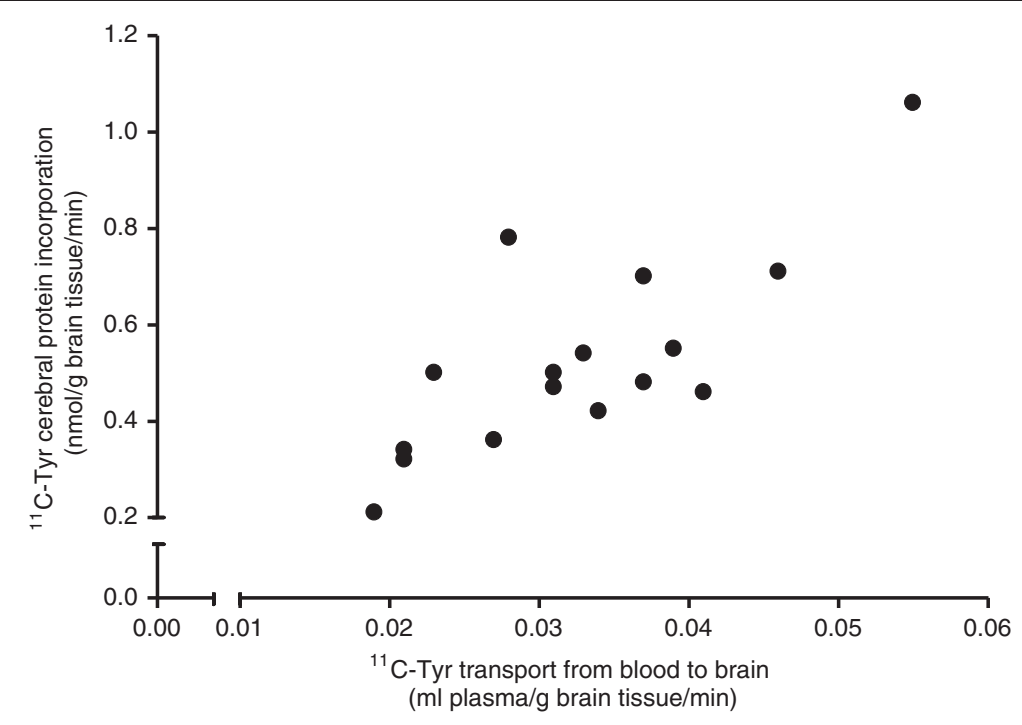

Figure 4 Relation between ${ }^{11} \mathrm{C}$-Tyr cerebral protein incorporation and ${ }^{11} \mathrm{C}$-Tyr transport from blood to brain.

In the ${ }^{11} \mathrm{C}$-Tyr influx regression model, both baseline Phe and ${ }^{11} \mathrm{C}$-Tyr efflux from brain to blood were found to be significant predictor variables. Of these two variables, baseline Phe showed the strongest association with ${ }^{11} \mathrm{C}$ Tyr influx. This strong association supports the concept that increased blood Phe concentrations reduce binding of blood non-Phe large neutral amino acids to the LAT1 transporter, thus reducing brain influx of these amino acids. The observed relationship between increased blood Phe concentrations and reduced ${ }^{11} \mathrm{C}$-Tyr influx could not have been biased by in vivo tyrosine synthesis, as flux analyses were performed for ${ }^{11} \mathrm{C}$-Tyr rather than $\mathrm{Tyr}$, and a standardized amount of ${ }^{11} \mathrm{C}$-Tyr was administered to each patient. The significant association between ${ }^{11} \mathrm{C}$-Tyr influx and ${ }^{11} \mathrm{C}$-Tyr efflux may be explained as follows. Similar to brain influx, brain efflux of large neutral amino acids is at least partly mediated by the LAT1 transporter [31]. In addition to LAT1 [32], other amino acid transport systems exist at the abluminal membrane of BBB endothelial cells, which similarly transport LNAAs in a competitive manner [33]. These transport systems may thus complement LAT1 in mediating LNAA efflux from brain to blood [31,33]. Therefore, increased brain Phe concentrations could competitively reduce ${ }^{11} \mathrm{C}$-Tyr efflux via several transporters, including LAT1. Such increased brain Phe concentrations likely occur at increased blood Phe concentrations, which in turn are significantly associated with reduced ${ }^{11} \mathrm{C}$-Tyr influx. Thus, reduced ${ }^{11} \mathrm{C}$-Tyr influx may be associated with reduced ${ }^{11} \mathrm{C}$-Tyr efflux. In the ${ }^{11} \mathrm{C}$-Tyr cerebral protein incorporation regression model, ${ }^{11} \mathrm{C}$-Tyr transport from blood to brain was found to be a significant predictor variable, whereas blood Phe concentration was not. Blood Phe concentration explained 57\% of the observed variance in ${ }^{11} \mathrm{C}$-Tyr transport from blood to brain. Thus, $43 \%$ of the observed variance could not be prediced by blood Phe concentration. This relatively large variance unexplained by blood Phe concentration may clarify why blood Phe concentration did not independently predict ${ }^{11} \mathrm{C}$-Tyr cerebral protein incorporation.

Only two subjects had blood Phe concentrations outside the $360-1000 \mu \mathrm{mol} / \mathrm{L}$ range. On the one side, this result could limit the predictive value of our models for patients with blood Phe concentrations outside the studied range. Therefore, to further validate our conclusions, more patients with Phe concentrations $<360 \mu \mathrm{mol} / \mathrm{L}$ and $>1000$ $\mu \mathrm{mol} / \mathrm{L}$ at the time of study (presumably associated with relatively high and low values for LNAA BBB influx and CPS) should be investigated. On the other side, the blood Phe range studied offers new insights. First, contrary to previous reports, our dataset systematically studies LNAA BBB transport and CPS in PKU patients with blood Phe concentrations $<1000 \mu \mathrm{mol} / \mathrm{L}$. In the study of Oldendorf et al. [22], only two patients had blood Phe concentrations below this value. In the study of Landvogt et al. [23], individual blood Phe concentrations are not presented. However, it can be deduced from these data that at most three patients had blood concentrations $<1000 \mu \mathrm{mol} / \mathrm{L}$. Second, the blood Phe range in our study includes $600 \mu \mathrm{mol} / \mathrm{L}$, the currently aimed treatment maximum for adults. Even in patients with blood Phe concentrations below this current treatment maximum, ${ }^{11} \mathrm{C}$ - $\mathrm{Tyr}$ transport from blood to brain was decreased compared to that observed at lower blood Phe concentrations. This finding suggests that the current treatment maximum may have to be lowered in order to obtain optimal cognitive development.

The results presented in this study may have both fundamental and clinical implications. Regarding the fundamental relevance, reduced CPS may be one of the main 
mechanisms by which untreated PKU results in mental retardation. CPS is involved in many processes during brain development, including neuronal differentiation, maturation, migration, synaptic plasticity, and the formation of functional networks [12,13]. Thus, reduced CPS may negatively affect cognition via many mechanisms. Indeed, in inherited mental retardation diseases other than PKU, reduced CPS has been described [13,34]. Clinically, our data underline the importance of continuing PKU treatment after early adulthood. CPS-dependent developmental processes continue into the third decade $[35,36]$, and CPS-dependent synaptic plasticity occurs lifelong [37]. Thus, also at adult age, reduced CPS could contribute to impaired cerebral functioning. Finally, the observation that both ${ }^{11} \mathrm{C}$-Tyr influx from blood to brain and cerebral protein incorporation are reduced in PKU patients considered to be well-treated, justifies the development of new treatments aiming to restore these abnormalities.

Follow-up studies should focus on the functional consequences of reduced CPS in PKU, as well as the identification of a safe blood Phe upper limit with regards to CPS. Another direction for future research is to identify the contributions of elevated brain Phe concentrations and reduced brain non-Phe LNAA concentrations to reduced CPS. Combination of PET with magnetic resonance spectroscopy allows for investigating the association between brain Phe concentrations and CPS.

In summary, we observed that reduced ${ }^{11} \mathrm{C}$-Tyr cerebral protein incorporation in early and continuously treated PKU patients is strongly associated with reduced ${ }^{11} \mathrm{C}-\mathrm{Tyr}$ transport from blood to brain. ${ }^{11} \mathrm{C}$-Tyr transport from blood to brain was significantly reduced at increasing blood Phe concentrations. These findings support the hypothesis that reduced CPS in PKU results from impaired LNAA transport from blood to brain. Our findings may serve as a starting point for both improving current treatment practice and developing new treatment strategies, in order to optimize cognitive outcome and quality of life in PKU patients.

\section{Abbreviations}

LAT1: Large neutral amino acid type I; BBB: Blood-brain barrier; CPS: Cerebral protein synthesis; LNAA: Large neutral amino acid; PET: Positron emission tomography; Phe: Phenylalanine; PKU: Phenylketonuria; Tyr: Tyrosine.

\section{Competing interests}

FJvS has received financial support from Nutricia and Merck Serono for research purposes and for advisory board membership. There are no additional potential sources of conflict of interest.

\section{Authors' contributions}

DJR, HWdV, AMJP, FJvS, and PJJS were involved in the study design and data collection. MJdG and MH performed the statistical analyses and wrote the manuscript, primarily supervised by FJvS. All authors were involved in critical appraisal of the results. DJR, AMJP, PJJS, and FJvS provided important contributions throughout the manuscript preparation process. All authors read and approved the final manuscript.

\section{Acknowledgements}

We are grateful to P. Modderman and dr. A. van Waarde for analytical support.

\section{Author details}

'Department of Metabolic Diseases, Beatrix Children's Hospital, University Medical Center Groningen, University of Groningen, Groningen, the Netherlands. ${ }^{2}$ Laboratory of Metabolic Diseases, Department of Laboratory Medicine, University Medical Center Groningen, University of Groningen, Groningen, the Netherlands. ${ }^{3}$ Center for Liver, Digestive and Metabolic Diseases, University Medical Center Groningen, University of Groningen, Groningen, the Netherlands. ${ }^{4}$ Department of Internal Medicine, University Medical Center Utrecht, Utrecht University, Utrecht, the Netherlands. ${ }^{5}$ Department of Nuclear Medicine and Molecular Imaging, University Medical Center Groningen, University of Groningen, Groningen, the Netherlands.

Received: 10 May 2013 Accepted: 21 August 2013

Published: 4 September 2013

\section{References}

1. Blau N, van Spronsen, Levy HL: Phenylketonuria. Lancet 2010, 376:1417-1427.

2. Huijbregts SC, de Sonneville LM, Licht R, van Spronsen FJ, Verkerk PH, Sergeant JA: Sustained attention and inhibition of cognitive interference in treated phenylketonuria: associations with concurrent and lifetime phenylalanine concentrations. Neuropsychologia 2002, 40:7-15.

3. Huijbregts SC, de Sonneville LM, van Spronsen FJ, Licht R, Sergeant JA: The neuropsychological profile of early and continuously treated phenylketonuria: orienting, vigilance, and maintenance versus manipulation-functions of working memory. Neurosci Biobehav Rev 2002, 26:697-712.

4. Channon S, German E, Cassina C, Lee P: Executive functioning, memory, and learning in phenylketonuria. Neuropsychology 2004, 18:613-620.

5. Channon S, Mockler C, Lee P: Executive functioning and speed of processing in phenylketonuria. Neuropsychology 2005, 19:679-686.

6. Anderson PJ, Wood SJ, Francis DE, Coleman L, Anderson V, Boneh A: Are neuropsychological impairments in children with early-treated phenylketonuria (PKU) related to white matter abnormalities or elevated phenylalanine levels? Dev Neuropsychol 2007, 32:645-668.

7. Moyle JJ, Fox AM, Arthur M, Bynevelt M, Burnett JR: Meta-analysis of neuropsychological symptoms of adolescents and adults with PKU. Neuropsychol Rev 2007, 17:91-101.

8. DeRoche K, Welsh M: Twenty-five years of research on neurocognitive outcomes in early-treated phenylketonuria: intelligence and executive function. Dev Neuropsychol 2008, 33:474-504.

9. Surtees R, Blau N: The neurochemistry of phenylketonuria. Eur J Pediatr 2000, 159(Suppl 2):109-113.

10. van Spronsen FJ, Hoeksma M, Reijngoud DJ: Brain dysfunction in phenylketonuria: is phenylalanine toxicity the only possible cause? $J$ Inherit Metab Dis 2009, 32:46-51.

11. de Groot MJ, Hoeksma M, Blau N, Reijngoud DJ, van Spronsen FJ: Pathogenesis of cognitive dysfunction in phenylketonuria: review of hypotheses. Mol Genet Metab 2010, 99(Suppl 1):86-89.

12. Rao MS, Jacobson M: In Developmental Neurobiology, Chapters 2, 5, 8, 9, 10. New York (NY): Kluwer Academic/Plenum Publishers; 2005.

13. Vaillend $\mathrm{C}$, Poirier R, Laroche S: Genes, plasticity and mental retardation. Behav Brain Res 2008, 192:88-105.

14. Greer PL, Greenberg ME: From synapse to nucleus: calcium-dependent gene transcription in the control of synapse development and function. Neuron 2008, 59:846-860.

15. Paans AM, Pruim J, Smit GP, Visser G, Willemsen AT, Ullrich K: Neurotransmitter positron emission tomographic-studies in adults with phenylketonuria, a pilot study. Eur J Pediatr 1996, 155(Suppl 1):78-81.

16. Hoeksma M, Reijngoud DJ, Pruim J, de Valk HW, Paans AM, van Spronsen FJ: Phenylketonuria: High plasma phenylalanine decreases cerebral protein synthesis. Mol Genet Metab 2009, 96:177-182.

17. Hargreaves KM, Pardridge WM: Neutral amino acid transport at the human blood-brain barrier. J Biol Chem 1988, 263:19392-19397.

18. Pardridge WM: Blood-brain barrier carrier-mediated transport and brain metabolism of amino acids. Neurochem Res 1998, 23:635-644.

19. Smith QR: Transport of glutamate and other amino acids at the bloodbrain barrier. J Nutr 2000, 130(Suppl):1016-1022. 
20. Oldendorf WH: Saturation of blood brain barrier transport of amino acids in phenylketonuria. Arch Neurol 1973, 28:45-48.

21. O'Mara M, Oakley A, Bröer S: Mechanism and putative structure of $B^{0}$-like neutral amino acid transporters. J Membrane Biol 2006, 213:111-118.

22. Oldendorf WH, Sisson BW, Silverstein A: Brain uptake of selenomethionine Se 75. II. Reduced brain uptake of selenomethionine Se 75 in phenylketonuria. Arch Neurol 1971, 24:524-528.

23. Landvogt $C$, Mengel $E$, Bartenstein $P$, Buchholz HG, Schreckenberger $M$, Siessmeier T, Scheurich A, Feldmann R, Weglage J, Cumming P, Zepp F, Ullrich $K$ : Reduced cerebral fluoro-L dopamine uptake in adult patients suffering from phenylketonuria. J Cereb Blood Flow Metab 2008, 28:824-831.

24. van Spronsen FJ: Phenylketonuria: a 21st century perspective. Nat Rev Endocrinol 2010, 6:509-514.

25. van Spronsen FJ, van Rijn M, Dorgelo B, Hoeksma M, Bosch AM, Mulder MF, de Klerk JBC, de Koning T, Estela Rubio-Gozalbo M, de Vries M, Verkerk PH: Phenylalanine tolerance can already reliably be assessed at the age of 2 years in patients with PKU. J Inherit Metab Dis 2009, 32:27-31.

26. Ishiwata K, Vaalburg W, Elsinga PH, Paans AM, Woldring MG: Metabolic studies with $\mathrm{L}-\left[1-{ }^{14} \mathrm{C}\right]$-tyrosine for the investigation of a kinetic model to measure protein synthesis rates with PET. J Nucl Med 1988, 29:524-529.

27. Willemsen AT, van Waarde A, Paans AM, Pruim J, Luurtsema G, Go KG, Vaalburg $W$ : In vivo protein synthesis rate determination in primary or recurrent brain tumors using L-[1- $\left.{ }^{11} \mathrm{C}\right]$-tyrosine and PET. J NuCl Med 1995, 36:411-419.

28. Cumming $P$, Ase A, Kuwabara $H$, Gjedde $\left.A:{ }^{3} H\right] D O P A$ formed from $\left[{ }^{3} \mathrm{H}\right]$ tyrosine in living rat brain is not committed to dopamine synthesis. J Cereb Blood Flow Metab 1998, 18:491-499.

29. Hawkins RA, Huang SC, Barrio JR, Keen RE, Feng D, Mazziotta JC, Phelps ME: Estimation of local cerebral protein synthesis rates with L-[1-11C]leucine and PET: methods, model, and results in animals and humans. $J$ Cereb Blood Flow Metab 1989, 9:446-460.

30. van Spronsen FJ, van Rijn M, van Dijk T, Smit GP, Reijngoud DJ, Berger R, Heymans HS: Plasma phenylalanine and tyrosine responses to different nutritional conditions (fasting/postprandial) in patients with phenylketonuria: effect of sample timing. Pediatrics 1993, 92:570-573.

31. Omidi Y, Barar J, Ahmadian S, Heidari HR, Gumbleton M: Characterization and astrocytic modulation of system $\mathrm{L}$ transporters in brain microvasculature endothelial cells. Cell Biochem Funct 2008, 26:381-391.

32. del Pino MM S, Peterson DR, Hawkins RA: Neutral amino acid transport characterization of isolated luminal and abluminal membranes of the blood-brain barrier. J Biol Chem 1995, 270:14913-14918.

33. O'Kane RL, Hawkins RA: $\mathrm{Na}^{+}$-dependent transport of large neutral amino acids occurs at the abluminal membrane of the blood-brain barrier. Am J Physiol Endocrinol Metab 2003, 285:E1167-E1173.

34. Johnston MV: Brain plasticity in paediatric neurology. Eur J Paediatr Neurol 2003, 7:105-113.

35. Aine CJ, Sanfratello L, Adair JC, Knoefel JE, Caprihan A, Stephen JM: Development and decline of memory functions in normal, pathological and healthy successful aging. Brain Topogr 2011, 24:323-339.

36. Petanjek Z, Judaš M, Šimic G, Rasin MR, Uylings HB, Rakic P, Kostovic I: Extraordinary neoteny of synaptic spines in the human prefrontal cortex. Proc Natl Acad Sci U S A 2011, 108:13281-13286.

37. Saneyoshi T, Fortin DA, Soderling TR: Regulation of spine and synapse formation by activity-dependent intracellular signaling pathways. Curr Opin Neurobiol 2010, 20:108-115.

doi:10.1186/1750-1172-8-133

Cite this article as: de Groot et al:: Phenylketonuria: reduced tyrosine brain influx relates to reduced cerebral protein synthesis. Orphanet Journal of Rare Diseases 2013 8:133.

\section{Submit your next manuscript to BioMed Central and take full advantage of:}

- Convenient online submission

- Thorough peer review

- No space constraints or color figure charges

- Immediate publication on acceptance

- Inclusion in PubMed, CAS, Scopus and Google Scholar

- Research which is freely available for redistribution

Submit your manuscript at www.biomedcentral.com/submit 